\title{
FAKTOR SOSIAL TERHADAP PENGELOLAAN RUANG TERBUKA HIJAU DI KAWASAN DESA RAWAN LONGSOR
}

\author{
Moch. Shofwan \\ Program Studi Perencanaan Wilayah dan Kota, Fakultas Teknik Sipil dan Perencanaan (FTSP) \\ Universitas PGRI Adi Buana Surabaya \\ Email : \\ shofwan.moch@unipasby.ac.id
}

\begin{abstract}
Green Open Space (RTH) is one of the balancing factors of an area in order to keep alignment to the dynamics of life around it. Social activity is part of the dynamics of society in building and managing a region. Social activities can not be separated from the existing institutions in the region, the institutional symbolized by the existence of groups (entities) that are capable of providing capacity for action on changes and policy making. Penanggungan village is a village whose territory is located on the slopes of the mountains, this village belongs to the category of villages prone to landslides. Social community of Penanggungan Village become the focus of study related to Green Open Space management factor $(R T H)$. The result of correlation analysis shows that there is a relationship between social condition and Green Open Space (RTH) that is obtained by significant value 0.000 which means less than 0.005 so that $\mathrm{HO}$ result is rejected $\mathrm{H} 1$ accepted, it means there is relationship between variable $X$ to $Y$. Based on result surveys in the field, most of Penanggungan Village which has 4 hamlets namely Ngembes, Penanggungan, Sendang, and Kemendung are entering the green area. This is in accordance with topographic conditions in the village Penanggungan into the topography that has an average height of 600-700 mdpl.
\end{abstract}

Keywords: Green Open Space, Social, Penanggungan Village.

\section{PENDAHULUAN}

Ruang Terbuka Hijau (RTH) merupakan salah satu faktor penyeimbang suatu wilayah agar tetap dapat memberikan penyelarasan terhadap dinamika kehidupan disekitarnya. Ketika Ruang Terbuka Hijau $(\mathrm{RTH})$ secara persentase tidak memenuhi persyaratan maka dapat dilihat dampak yang ditimbulkan disekitar wilayah tersebut. Salah satu akibat berkurangnya Ruang Terbuka Hijau (RTH) adalah meningkatnya jumlah penduduk yang berakibat meningkatnya sektor pembangunan kawasan terbangun, dengan kata lain peningkatan penduduk mengakibatkan peningkatan lahan terbangun sekaligus pengurangan Ruang Terbuka Hijau (RTH) (Kodoatie, 2013). 


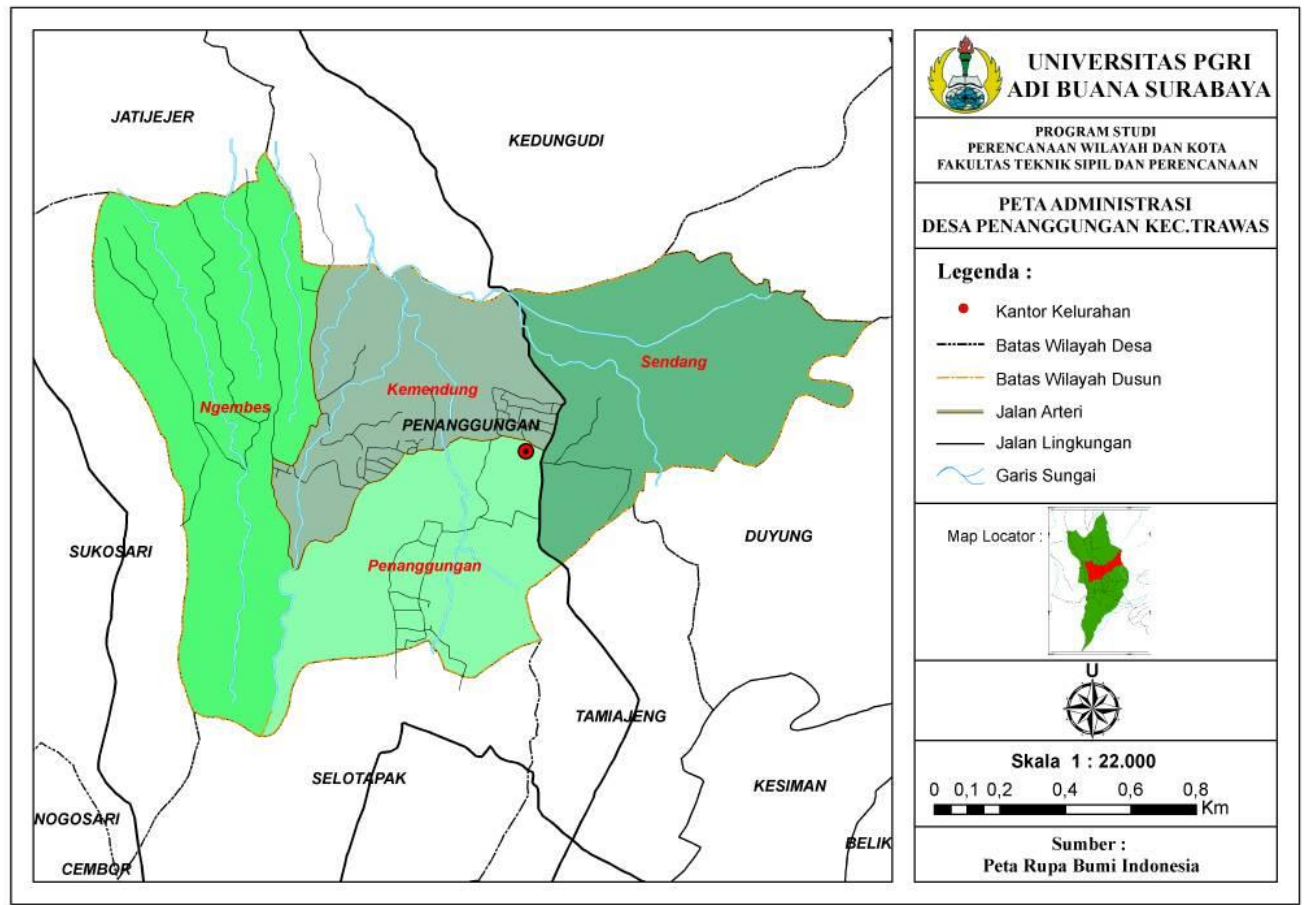

Gambar 1. Peta Administrasi Desa Penanggungan

Aktifitas sosial merupakan bagian dari dinamika masyarkat dalam membangun dan mengelola suatu wilayah. Kegiatan sosial tidak terlepas dari kelembagaan yang ada di wilayah tersebut, kelembagaan disimbolkan dengan adanya kelompok (entitas) yang secara kapasitas mampu memberikan aksi terhadap perubahan dan pengambilan kebijakan, salah satunya menurut Gibson (1997) dalam (Hariadi, 2011) bahwa adanya power legitimasi (legitimate power) adalah kemampuan seseorang untuk mempengaruhi orang lain karena posisinya. Desa Penanggungan merupakan desa yang wilayahnya terletak di lereng pegunungan, desa ini tergolong kategori desa yang rawan longsor. Sosial masyarakat Desa Penanggungan menjadi fokus kajian kaitannya dengan faktor pengelolaan Ruang Terbuka Hijau (RTH) dikawasan desa tersebut.

\section{METODOLOGI PENELITIAN}

\section{Unit Analisis}

Unit analisis dalam penelitian ini adalah Desa Penanggungan Kecamatan Trawas Kabupaten Mojokerto. Desa
Penanggungan secara geografis wilayahnya terletak di kawasan rawan bencana longsor.

\section{Metode Pengumpulan Data}

Metode pengumpulan data merupakan salah satu prosedur/mekanisme untuk mendapatkan kondisi riil pada suatu obyek penelitian. Pada tahap pengumpulan data dilakukan pemahaman terhadap karakteristik dari variabel-variabel yang akan diamati pada wilayah studi.

Metode pengumpulan data ditinjau dari sumber data yang akan diamati, yaitu :

1. Survei Data Primer

Survei data primer merupakan survei yang dilakukan dengan turun langsung ke lapangan atau obyek studi. Dalam pengumpulan data primer dilakukan dengan dua cara pendekatan :

\section{a. Kuesioner}

Kuesioner sebagai alat pengambilan data yang berbentuk pertanyaanpertanyaan yang mengacu pada variable-variabel penelitian.

\section{b. Observasi}

Pengamatan dengan menggunakan indera penglihatan terhadap dinamika 
yang ada di wilayah penelitian, serta tidak dengan mengajukan pertanyaan-pertanyaan.

2. Data Sekunder

Survei sekunder adalah survei yang dilakukan dengan tidak turun langsung ke lapangan melainkan mengumpulkan data atau informasi dari beberapa sumber seperti instansi terkait dan literatur. Data sekunder biasanya telah tersusun dalam bentuk dokumendokumen.

\section{Variabel dan Teknik Analisis}

Variabel yang akan diteliti yaitu untuk menjawab rumusan masalah yang telah diuraikan. Berikut dapat dilihat pada tabel 1. Tabel 1. Variabel Penelitian

\begin{tabular}{|c|c|c|c|}
\hline Tujuan & Sub Variabel & Sumber & $\begin{array}{c}\text { Teknik } \\
\text { Analisis }\end{array}$ \\
\hline $\begin{array}{l}\text { Menganalisis } \\
\text { sosial } \\
\text { masyarakat }\end{array}$ & $\begin{array}{ll}\text { - Jaringan } & \text { Sosial } \\
& \text { Selembagaan }\end{array}$ & $\begin{array}{l}\text { - Kuesioner } \\
\text { - Observasi }\end{array}$ & $\begin{array}{l}\text { - Deskriptif } \\
\text { Kualitatif, } \\
\text { Kuantitatif } \\
\text { Eksploratif }\end{array}$ \\
\hline $\begin{array}{l}\text { Menganalisis } \\
\text { ruang } \\
\text { terbuka hijau }\end{array}$ & $\begin{array}{ll}\text { - } & \text { Luas RTH } \\
\text { - } & \text { Pemanfaatan } \\
& \text { RTH }\end{array}$ & $\begin{array}{l}\text { - Data spasial } \\
\text { dengan } \\
\text { mengguakan } \\
\text { sistem } \\
\text { informasi } \\
\text { geografis } \\
\text { - Observasi }\end{array}$ & $\begin{array}{l}\text { - Analisis } \\
\text { Spasial }\end{array}$ \\
\hline
\end{tabular}

Sumber: Hasil kompilasi, 2017

3. HASIL DAN PEMBAHASAN

Setelah melakukan penelitian dan berdasarkan data yang telah terkumpul langkah berikutnya adalah menyajikan data, menganalisis data, dan menguji hipotesis.

1. Penyajian Data

Penulis akan menyajikan data yang telah diambil selama penelitian dalam bentuk penyebaran kuesioner yang bersisi 50 butir pertanyaan yang terbagi atas 2 (dua) variabel sebagai berikut :

Tabel 2. Hasil Skoring Kuesioner Tahun

\begin{tabular}{clcc}
\multicolumn{4}{c}{2017} \\
\hline No & $\begin{array}{c}\text { Nama } \\
\text { Responden }\end{array}$ & $\begin{array}{c}\text { Kondisi Sosial } \\
(\mathbf{Y})\end{array}$ & $\begin{array}{c}\text { RTH } \\
(\mathbf{X})\end{array}$ \\
\hline 1 & Sulatri & 28 & 29 \\
2 & Nur Cahyadi & 29 & 30 \\
3 & Hasan & 28 & 29 \\
4 & Nuriyah Indah K. & 28 & 26
\end{tabular}

\begin{tabular}{clcc}
\hline No & $\begin{array}{c}\text { Nama } \\
\text { Responden }\end{array}$ & $\begin{array}{c}\text { Kondisi Sosial } \\
(\mathbf{Y})\end{array}$ & $\begin{array}{c}\text { RTH } \\
(\mathbf{X})\end{array}$ \\
\hline 5 & Nanik & 31 & 27 \\
6 & Hasyim & 33 & 26 \\
7 & Hasanah & 29 & 29 \\
8 & Titin & 31 & 28 \\
9 & Mudrik & 27 & 29 \\
10 & Wahidin & 26 & 27 \\
11 & Sugeng & 27 & 27 \\
12 & Siti Masila & 27 & 27 \\
13 & Mufida & 31 & 26 \\
14 & Mutmainnah & 28 & 27 \\
15 & Riska Aditia & 27 & 26 \\
16 & Kartiningsih & 30 & 27 \\
17 & Susi & 27 & 28 \\
18 & Choiroh & 28 & 38 \\
19 & Sutinah & 27 & 28 \\
20 & Sumi & 31 & 31 \\
21 & Siti Rukoyah & 32 & 29 \\
22 & Sulaiman & 31 & 30 \\
23 & Fitri Mardiyah & 29 & 28 \\
24 & Suci & 31 & 28 \\
25 & Sulastri Hayat & 32 & 27 \\
26 & Samsul & 30 & 29 \\
27 & Hadi & 28 & 27 \\
28 & Suherman & 27 & 26 \\
29 & Kusnadi & 27 & 28 \\
30 & Hamidah & 27 & 27 \\
\hline Sum & & \\
\hline
\end{tabular}

Sumber: Hasil Analisa, 2017

Untuk mengetahui seberapa besar korelasi atau hubungan antara kondisi Ruang Terbuka Hijua (RTH) terhadap kondisi sosial dapat menggunakan SPSS 21 yaitu analisis korelasi. Berikut hasil analisis korelasi adalah sebagai berikut :

Tabel 3. Hasil Analisis Korelasi

\begin{tabular}{lccc}
\hline \multicolumn{4}{c}{ Descriptive Statistics } \\
\hline & Mean & Std. Deviation & $\mathrm{N}$ \\
Sosial & 2.00 & .000 & 30 \\
Ruang & & & \\
Terbuka & 1.00 & .000 & 30 \\
Hijau & & & \\
\hline \multicolumn{4}{c}{ Correlations } \\
\hline
\end{tabular}




\begin{tabular}{llcc}
\hline & & Sosial & $\begin{array}{c}\text { Ruang } \\
\text { Terbuka } \\
\text { Hijau }\end{array}$ \\
$\begin{array}{llcc}\text { Pearson } \\
\text { Correlation }\end{array}$ & $\begin{array}{l}\text { Sosial } \\
\text { Ruang } \\
\text { Terbuka } \\
\text { Hijau } \\
\text { Sig. (1- }\end{array}$ & 1.000 & $\cdot$ \\
tailed) & $\begin{array}{l}\text { Sosial } \\
\text { Ruang } \\
\text { Terbuka }\end{array}$ &. & 1.000 \\
& $\begin{array}{l}\text { Hijau } \\
\text { Sosial } \\
\text { Ruang }\end{array}$ & 30 & .000 \\
& $\begin{array}{l}\text { Terbuka } \\
\text { Hijau }\end{array}$ & 30 & 30 \\
Sumber: & Hasil Perhitungan SPSS 21, 2017
\end{tabular}

Hasil analisis menunjukkan bahwa korelasi yang terjadi hanya antara kondisi sosial dengan Ruang Terbuka Hijau (RTH) diketahui siginifikan sebesar 0,001 .

Interpretasi hasil analisis dilakukan dengan:

1. Susun Hipotesis: HO : Tidak ada hubungan X terhadap $\mathrm{Y}$

H1 : Ada hubungan positif dan signifikan X terhadap Y

2. Menetapkan taraf signifikan 0,05

3. Membandingkan signifikansi yang ditetapkan dengan sinifikan yang diperoleh dari analisis (Sig.)

Bila nilai Sig. > a $(0,05)$, maka

H0 diterima, H0 ditolak,

Bila nilai Sig. < a $(0,05)$, maka

Berdasarkan hasil analisis SPSS 21 yaitu menggunakan analisis korelasi atau hubungan menunjukkan bahwa nilai Sig. $(0.000)<$ a (0.005). Dengan semikian dapat disimpulkan bahwa H0 ditolak. Artinya ada hubungan yang signifikan antara kondisi sosial terhadap kondisi Ruang Terbuka Hijau ( RTH) di Desa Penanggungan Kecamatan Trawas Kabupaten Mojokerto.

\section{PEMBAHASAN}

Hasil analisis korelasi, menunjukkan bahwa terdapat hubungan antara kondisi sosial dan Ruang Terbuka Hijau (RTH) yaitu dengan diperoleh nilai signifikan sebesar 0.000 yang artinya lebih kecil dari 0.005 sehingga diperoleh hasil H0 ditolak H1 diterima, artinya terdapat hubungan antara variabel $\mathrm{X}$ terhadap $\mathrm{Y}$. Berdasarkan hasil survei di lapangan, sebagian besar Desa Penanggungan yang memiliki 4 dusun yaitu Dusun Ngembes, Dusun Penanggungan, Dusun Sendang, dan Dusun Kemendung adalah masuk dalam kawasan hijau. Hal ini sesuai dengan kondisi topografi di Desa Penanggungan masuk dalam topografi yang memiliki ketinggan rata-rata 600-700 mdpl sehingga masuk dalam kontur pegunungan atau bukit. Oleh itu, karena masuk dalam kawasan pegunungan atau perbukitan sehingga untuk daerah ruang hijaunya tentunya sangat banyak dijumpai, mulai dari area persawahan dan perkebunan yang keduanya masuk dalam kawasan Ruang Terbuka Hijau (RTH). Ruang terbuka hijau di Desa Penanggungan berupa pemakaman dan lapangan hijau, dan untuk sarana taman lingkungan atau RW masih belum tersedia. Namun, hal ini tidak menjadi kendala karena dengan kondisi desa yang berada di pegunungan dan perbukitan maka untuk tidak ketersediaan taman lingkungan atau RW bukanlah menjadi hal yang masalah. Pada setiap dusun d Desa Penanggungan sudah tersedia pemakaman dan lapangan hijau yang sudah mampu melayani penduduk sekitarnya.

Selain terdapat pemakaman dan lapangan hijau, di Desa Penanggungan juga memiliki potensi alam yang sangat melimpah yakni pada bidang pertanian dan perkebunan. Pertanian berupa padi yang sebagian besar adalah milik warga Desa Penanggungan, sedangkan untuk perkebunan sebagaian besar adalah milik pihak swasta dan pemerintah. Karena memang Desa Penanggungan masuk dalam kawasan hutan lindung yang artinya hutan yang dilindungi oleh pemerintah daerah setempat. Berdasarkan penggunaan lahan di Desa Penanggungan adalah sebagian besar pertanian tanah kering semusim, misalnya tanaman sayuran seperti cabai, tomat dan lain sebagainya. Kondisi Ruang Terbuka Hijau sudah seharusnya harus tetap dilestarikan dan dilindungi agar nantinya dapat dirasakan dan dinikmati untuk generasi mendatang. Pelestarian ini tentunya dapat terjaga dari sosial masyarakat Desa Penanggungan itu 
sendiri. Desa Penanggungan termasuk kawasan yang rawan bencana longsor, karena secara kemiringan lereng masih banyak yang diatas $40 \%$ dan terdapat banyak pembangunan, sehingga diperlukan upaya intensif untuk mengelola kawasan tersebut.

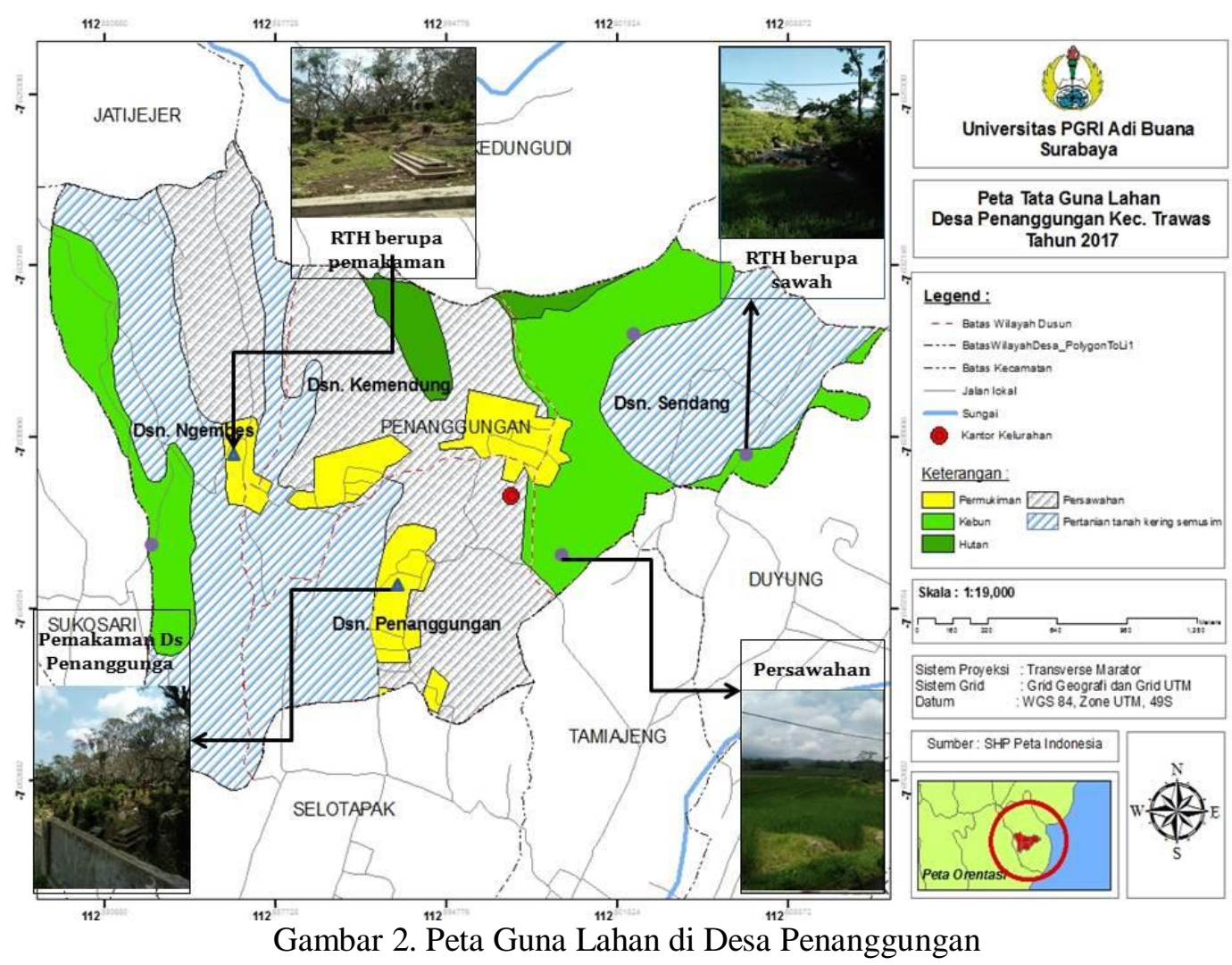

Kondisi sosial di Desa Penanggungan masih terjalin dengan baik antar warga dan juga antar dusun. Hal ini dapat dilihat, yakni masih terdapatnya kegiatan warga seperti bersih desa atau ruwatan desa yang diadakan setiap 3 tahun sekali. Kegiatan ini adalah kegiatan membersihkan desa agar terhindar dari bencana apapun. Kegiatan yang dilakukan dibalai Desa Penanggungan diikuti oleh seluruh warga dusun di desa tersebut yaitu Dusun Ngembes, Dusun Penanggungan, Dusun Sendang, dan Dusun Kemendung. Biasanya warga membawa seserahan berupa hasil bumi berupa sayuran atau buah-buahan untuk diarak mengelilingi desa. Selain itu, kondisi sosial dimasyarakat yang masih terjalin adalah masih terdapatnya kegiatan kerja bakti setiap dusun yang dilakukan setiap minggu sekali. Kegiatan warga ini biasanya bersih-bersih kampung dan juga kerja bakti pembangunan jalan. Selain itu, kerja bakti ini juga biasanya berupa penataan kembali potpot bunga yang disetiap rumah harus mempunyai tanaman hias.

Berdasarkan pembahasan dari kedua variabel tersebut, maka dapat disimpulkan bahwa terdapat hubungan antara kondisi Ruang Terbuka Hijau (RTH) dan kondisi sosial masyarakat. Kondisi Ruang Terbuka Hijau (RTH) berupa pertanian dan perkebunan tanpa adanya perawatan yang dilakukan oleh warga dengan baik maka akan mengalami kondisi tidak terawat dan kurang baik. Perawatan ini adalah salah satu sosial masyarakat yang masih terjaga di Desa Penanggungan berupa kerja bakti bersih desa/dusun. 
Tabel 4. Trasek Desa Penanggungan

\begin{tabular}{|c|c|c|c|c|}
\hline & $\begin{array}{c}\text { Dusun } \\
\text { Penanggungan }\end{array}$ & Dusun Sendang & $\begin{array}{c}\begin{array}{c}\text { Dusun } \\
\text { Kemendung }\end{array} \\
\end{array}$ & $\begin{array}{c}\text { Dusun } \\
\text { Ngembes }\end{array}$ \\
\hline $\begin{array}{l}\text { Pola } \\
\text { Permukiman }\end{array}$ & Menyebar & Menyebar & Menyebar & Menyebar \\
\hline $\begin{array}{l}\text { Penggunaan } \\
\text { Lahan }\end{array}$ & $\begin{array}{l}\text { - } \text { Permukiman } \\
\text { - Pertanian, } \\
\text { - Peternakan } \\
\text { - Pekarangan, } \\
\text { - Tegalan dan } \\
\text { - Perkebunan } \\
\quad \text { swasta } \\
\end{array}$ & $\begin{array}{l}\text { - Permukiman } \\
\text { - Pertanian } \\
\text { - Peternakan } \\
\text { - Pekarangan, } \\
\text { - Tegalan dan } \\
\text { - Perkebunan } \\
\text { swasta } \\
\end{array}$ & $\begin{array}{l}\text { - Permukiman } \\
\text { - Pertanian } \\
\text { - Peternakan } \\
\text { - Pekarangan } \\
\text { - Tegalan dan } \\
\text { - Perkebunan } \\
\quad \text { swasta } \\
\end{array}$ & $\begin{array}{l}\text { - Permukiman } \\
\text { - Pertanian } \\
\text { - Peternaka } \\
\text { - Pekarangan } \\
\text { - Tegalan dan } \\
\text { - Perkebunan } \\
\text { swasta } \\
\end{array}$ \\
\hline Topografi & Dataran Tinggi & Dataran Tinggi & Dataran Tinggi & Dataran Tinggi \\
\hline Ketinggian & 600-700 mdpl & $600-700$ meter & $600-700$ meter & $600-700$ meter \\
\hline Sumber Air & Sumur bor & Sumber mata air & Sumber mata air & Sumber mata air \\
\hline Jenis Tanah & Alluvial & Alluvial & Alluvial & Alluvial \\
\hline Fasilitas & $\begin{array}{l}\text { - } \text { Masji } \\
\text { - } \text { Mushola } \\
\text { - } \text { pos kampling } \\
\text { - SD } \\
\text { - SLTP } \\
\text { - SLTA } \\
\text { - madrasah } \\
\text { - diniyah } \\
\text { - lapangan } \\
\end{array}$ & $\begin{array}{l}\text { - Mushola } \\
\text { - Pos Kampling }\end{array}$ & $\begin{array}{l}\text { - } \text { Mushola } \\
\text { - Pos Kampling } \\
\text { - Lapangan } \\
\text { - Pukesmas } \\
\\
\text { pembantu }\end{array}$ & $\begin{array}{l}\text { - Mushola } \\
\text { - Pos kampling }\end{array}$ \\
\hline Potensi & $\begin{array}{ll}\text { - } & \text { Pertanian } \\
\text { - } & \text { Pertenakan } \\
\text { - } & \text { Tempat Wisata } \\
& \text { Air Terjun, } \\
\end{array}$ & $\begin{array}{l}\text { - Pertanian } \\
\text { - Pertenakan dan } \\
\text { - Perkebunan }\end{array}$ & $\begin{array}{l}\text { - Pertanian, } \\
\text { - Pertenakan dan } \\
\text { - Perkebunan }\end{array}$ & $\begin{array}{l}\text { - Pertanian } \\
\text { - Pertenakan } \\
\text { dan } \\
\text { - Perkebunan }\end{array}$ \\
\hline Masalah & $\begin{array}{l}\text { - Akses jalan } \\
\text { menuju wisata } \\
\text { air terjun } \\
\text { masih kurang } \\
\text { baik } \\
\text { - penerangan } \\
\text { jalan kurang }\end{array}$ & $\begin{array}{l}\text { - Terdapat } \\
\text { permukiman } \\
\text { non permanen } \\
\text { - penerangan } \\
\text { jalan masih } \\
\text { kurang }\end{array}$ & 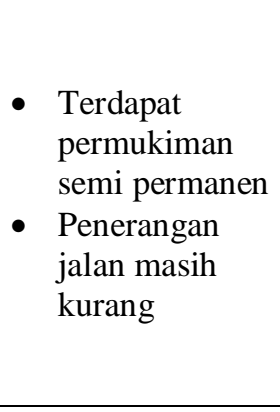 & $\begin{array}{l}\text { - Terdapat } \\
\text { permukiman } \\
\text { non } \\
\text { permanen, } \\
\text { - pemerataan } \\
\text { sumber air } \\
\text { belum baik, } \\
\text { - penerangan } \\
\text { jalan masih } \\
\text { kurang } \\
\end{array}$ \\
\hline
\end{tabular}

Sumber: Hasil Observasi, 2017

\section{KESIMPULAN}

Berdasarkan hasil studi yang telah dilakukan dapat ditarik kesimpulan untuk merangkum hasil analisis kondisi sosial terhadap Ruang Terbuka Hijau (RTH) di Desa Penanggungan Kecamatan Trawas Kabupaten Mojokerto.
Kesimpulan yang dapat diambil adalah sebagai berikut:

1. Dalam aspek budaya, masyarakat Desa Penanggungan sangat menjunjung tinggi kearifan lokal. Hal ini tercermin dalam 
kehidupan sehari-hari baik dalam berbagai acara seni dan budaya keagamaan.

2. Hasil analisis yang menggunakan SPSS 21 dengan menggunakan 2 (dua) variabel yaitu kondisi sosial dan Ruang Terbuka Hijau (RTH) di Desa Penanggungan yang menggunakan analisis korelasi atau hubungan menunjukkan bahwa nilai Sig. $(0.000)<$ a (0.005). Dengan semikian dapat dsimpulkan bahwa H0 ditolak. Artinya ada hubungan yang signifikan antara kondisi sosial dan kondisi Ruang Terbuka Hijau (RTH) di Desa Penanggungan Kecamatan Trawas Kabupaten Mojokerto.

\section{Ucapan Terima Kasih}

Ucapan terima kasih ditujukan kepada Program Studi Perencanaan Wilayah dan Kota, Fakultas Teknik Sipil dan Perencanaan, Universitas PGRI Adi Buana (UNIPA) Surabaya sebagai wadah pengembangan keilmuan.

\section{DAFTRA PUSTAKA}

BPS (Badan Pusat Statistik). Tahun 2015. Mojokerto dalam Angka.

Hariadi, Sunarru Samsi. 2011. Dinamika Kelompok. Yogyakarta: Sekolah Pascasarjana Universitas Gadjah Mada.

Kodoatie, Robert J. 2013. Rekayasa dan Manajemen Banjir Kota. Yogyakarta: CV. Andi Offset.

Sugiyono, 2013. Metode Penelitian Kombinasi (Mixed Methods). Bandung: Alfabeta .

UURI No. 26 Tahun 2007 tentang penataan ruang, LNRI Tahun 2007 Nomor 68; TLNRI Nomor 4725 